\title{
Characterizing Disparities in Risky Alcohol Use, Tobacco Smoking, E-Cigarette Use and Physical Inactivity Among Cancer Survivors in the United States
}

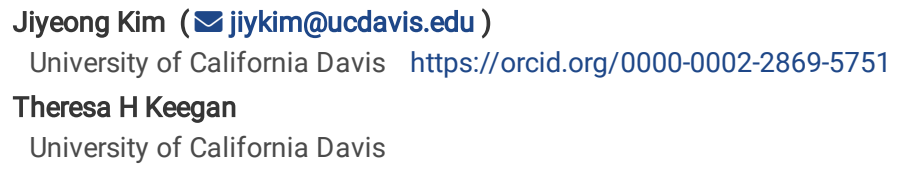

Research Article

Keywords: Cancer survivors, unhealthy behavior, alcohol consumption, tobacco smoking, e-cigarette use, physical inactivity

Posted Date: March 8th, 2022

DOI: https://doi.org/10.21203/rs.3.rs-1397958/v1

License: @ (i) This work is licensed under a Creative Commons Attribution 4.0 International License. Read Full License 


\section{Abstract \\ Purpose.}

Unhealthy lifestyle behaviors are associated with inferior health outcomes among cancer survivors, including increased mortality. It is crucial to identify vulnerable subgroups, yet investigations have been limited. Thus, this study aimed to examine sociodemographic and clinical characteristics associated with risky health behaviors among cancer survivors.

\section{Methods.}

We used national survey data (Health Information National Trends Survey, HINTS 2017-2020) for 2,579 cancer survivors. We calculated the prevalence of risky alcohol use, current tobacco smoking, e-cigarette use, and not meeting physical activity guidelines. We performed weighted logistic regression to obtain multivariable-adjusted odds ratios (OR) for the association between each unhealthy behavior with sociodemographic and clinical characteristics.

\section{Results.}

Overall, $25 \%$ showed risky alcohol use, $12 \%$ were current tobacco smokers, $3 \%$ were current e-cigarette users, and $68 \%$ did not meet physical activity guidelines. Cancer survivors who were males, non-Hispanic Whites or African Americans, without a college education, not married, with comorbidities or psychological distress were more likely to have unhealthy behaviors. Those with lung disease or depression were 2 times more likely to smoke tobacco or ecigarettes and those with psychological distress were more 1.6 times more likely to be physically inactive. Moreover, risky drinkers $(\mathrm{OR}=1.75,95 \% \mathrm{Cl}=1.22-$ 2.52) and e-cigarette smokers $(\mathrm{OR}=16.40,95 \% \mathrm{Cl} 3.29-81.89)$ were more likely to be current tobacco smokers.

\section{Conclusions}

We identified vulnerable subpopulations of cancer survivors with multiple unhealthy lifestyle behaviors.

\section{Implications for Cancer Survivors}

. Our findings inform clinicians and program and policy makers of the subgroups of cancer survivors to target for multiple health behavior interventions.

\section{Introduction}

In 2020, an estimated 19.3 million cancer survivors were in the U.S. [1]. Along with the early detection, adjuvant therapy, advanced medical procedures, and development of new cancer therapeutics, the number of people living with cancer is expected to increase [2]. Health behaviors, including alcohol consumption, tobacco use, and physical inactivity, can play important roles in improving mental health and cognitive function, physical health status, and health-related quality of life for cancer survivors.

Alcohol use increases the risk of cancer recurrence [3] or developing secondary malignancies in cancer survivors [4-11]. Among almost 100,000 head and neck cancer survivors, $13 \%$ of secondary malignancies were considered alcohol-associated, although the relationship of post-diagnosis alcohol consumption with recurrence and survival has been found to be inconsistent in other cancer types [12-14]. In addition, tobacco use is often associated with inferior disease outcomes, including increased all-cause or cancer specific mortality, in cancer survivors [15-23]. Although e-cigarettes were introduced as an alternative to quit tobacco smoking, recent studies found that it increased cancer risk and facilitated cancer progression [24-27] and its use is increasing among cancer survivors [28]. Moreover, moderate physical activity is associated with improvements in cancer-specific as well as all-cause mortality across 11 different types of cancer [29], and decreases in cancer recurrence among breast, colon, and prostate cancer survivors [30-32]. Due to the importance of health promotion strategies in cancer survivors, guidelines have been established for this population [33-37]. However, multiple studies found that that many cancer survivors do not meet health behavior guidelines [4-6, 38, 39]. A recent large cohort study showed that $14 \%$ of breast cancer survivors consumed alcohol daily and $18 \%$ were current tobacco users [5]. Nearly $70 \%$ of cancer survivors did not achieve the physical activity guidelines in the U.S., and up to $24 \%$ were current smokers [40].

Moreover, some studies identified subgroups of cancer survivors, defined by sociodemographic factors (e.g., age, sex), clinical status (e.g., psychological distress, cancer types, time since diagnosis), and treatment-related determinants [5, 41, 42], with unhealthy behaviors. For example, in a review, DemarkWahnefried et al. reported male, older, less-educated, or urban residing cancer survivors were less likely to be successful at adopting and keeping healthy lifestyle behaviors [39]. Furthermore, previous studies reported the associations between multiple unhealthy behaviors in cancer survivors. For example, alcohol intake and physical inactivity were associated among breast cancer survivors [14].

However, limited studies have examined the health behaviors of cancer survivors by sociodemographic or clinical factors to specify subgroups with disparities $[5,14,41,42,44,46-50]$ and those that have considered these associations were often limited to certain cancer types (e.g., breast, thyroid, head and neck, prostate, colorectal, or gastric cancer) $[5,14,38,43,45-48]$ or were conducted more than a decade ago when e-cigarette use was uncommon [14, 39, 44-47]. Identifying the subgroups of cancer survivors who are vulnerable to adopting and maintaining healthy lifestyles will be crucial to identify targeted populations for interventions to manage overall health and improve survival. Therefore, this study aims to examine unhealthy behaviors, including alcohol consumption, tobacco and e-cigarette use, and physical inactivity, among cancer survivors in the U.S. 


\section{Method}

\section{Data source}

The present study used publicly available, cross-sectional data from the Health Information National Trends Survey (HINTS) [49]. HINTS is a nationally representative survey collected by the National Cancer Institute. This study used HINTS 5 Cycle 1, 2, 3, and 4 in 2017-2020. HINTS 5 is a random digit-dialed telephone survey or a mailed questionnaire survey in non-institutionalized civilians aged 18 and older in the U.S. Geographic addresses were stratified by two areas with high concentration of minority population or low concentration of minority population in HINTS 5 Cycle 2, 3, and 4. HINTS 5 Cycle 1 included one more stratification in geographic address, counties of Central Appalachia. Our study followed the Strengthening the Reporting of Observational Studies in Epidemiology (STROBE) guidelines [50]. The total number of survey respondents in this study were 16,092. 3,285 from Cycle 1, 3,504 from Cycle 2, 5,438 from Cycle 3, and 3,865 from Cycle 4. Each response rate was $32.4 \%, 32.4 \%, 30.3 \%, 36.7 \%$, respectively [49]. Data received full sample weights for the sample to be nationally representative. 50 replicate weights were applied to calculate standard errors as suggested by HINTS analysis recommendations. The fullsample weight accounted for household-level base weight, non-response, person-level initial weight and other biases [51].

\section{Cancer survivor status}

Consistent with the National Cancer Institute definition of cancer survivor [52], cancer survivor status in this study was identified by the question; "Have you ever been diagnosed as having cancer?" Those who affirmatively responded 'yes' were defined as cancer survivor. Using the question, "At what age, were you first told you had a cancer?" HINTS calculated time since cancer diagnosis and provided it in 4 levels: less than 1 year, 2-5 years, 6-10 years, more than 11 years. Participants reported their cancer types and were classified as having breast, cervical, prostate, colon, lung, skin cancer, melanoma, multiple cancers, and other cancers. Other cancers included bladder, bone, endometrial, head and neck, leukemia/blood, liver, lymphoma (Hodgkin's and non-Hodgkin's), oral, ovarian, pancreatic, pharyngeal, rectal, renal, and stomach cancer.

\section{Outcome variables}

\section{Alcohol consumption}

To investigate the number of average drinks per week, we used data derived from two survey questions about average number of drinks per day and the number of days of having at least one drink per week during the past 30 days. We categorized alcohol consumption per week into light (0-3), moderate (4-6), heavy $(\geq 7)$ drinks, as done previously $[42,53]$. While there has been no consensus on the alcohol consumption guidelines for cancer survivors, we primarily referred to the National Health Interview Survey (NHIS)- categories [53]. Then, we combined moderate and heavy drinking as risky alcohol use because American Cancer Society (ACS) and International Agency for Research on Cancer (IARC) both consider these high risk groups [42, 54, 55].

\section{Tobacco use}

To investigate the current smoking status, the following questionnaire was used. "How often do you now smoke?" Respondents who answered, "Every day", "Some days" were considered as current smokers. To investigate the current e-cigarette smoking status, the similar questionnaire was used. "Do you now use e-cigarette every day, some days, or not at all?" If respondents answered, "Every day", or "Some days", they were considered as current smokers or e-cigarette smokers, as done previously [42].

\section{Physical activity}

To investigate the weekly minutes of moderate exercise, data from two survey questionnaires about the number of days of moderate exercise (such as brisk walking, bicycling at a regular pace, and swimming at a regular pace) per week and minutes of moderate exercise per day were used. We categorized the level of physical activity into two groups; physically active (more than 150 minutes of weekly moderate exercise) and physically inactive (0-150 minutes of weekly moderate exercise) based on the U.S. Physical Activity Guidelines [56, 57].

\section{Covariates}

The conceptual framework of social determinants of health from the Healthy People 2030 [58] was applied for the choices of sociodemographic predictors in this study: Age (18 to 34, 35 to 49, 50 to 64, 65 to 74, 75 or older), birth gender (male, female), race/ethnicity (non-Hispanic White, Non-Hispanic Black/African American, Hispanic, non-Hispanic Asian, Other), household income ( $<20,000, \$ 20,000$ to $<\$ 35,000, \$ 35,000$ to $<\$ 50,000, \$ 50,000$ to $<\$ 75,000, \$ 75,000 £$ ), educational attainment (less than high school, high school graduate, some college, college graduate or more), marital status (married or living with a romantic partner as a married vs. not married including divorced, widowed, separated, single/never been married), employment status (employed vs. unemployed including homemaker, student, retired, disabled), health insurance type (insured by employment, private insurance, Medicaid, Medicare, Tricare, Veterans Affairs, Indian Health Services), rurality of residence (metropolitan, micropolitan, small town, rural). Rurality was determined by Urban Rural Commuting Area (RUCA) that categorizes census tracts based on population density, urbanization, commuting patterns developed by United Status Department of Agriculture [59]. Clinical predictors included medical conditions (diabetes, high blood pressure, heart disease, lung disease, arthritis, depression) and psychological distress (little interest, hopelessness, nervousness, worrying).

\section{Statistical analysis}

In descriptive analysis, we conducted a Chi-Square (categorical data) and a t-test (continuous data) to demonstrate demographic and clinical characteristics of cancer survivors and the prevalence of unhealthy behaviors (alcohol consumption, tobacco use, e-cigarette use, physical inactivity). Categorical data was presented with frequency ( $\mathrm{n}$ ) and weighted percentage (\%) and continuous data was presented with mean and standard deviation (Table 1 and 2 ). Survey 
weighted multivariate logistic regression was performed to estimate the odds of alcohol consumption (light, moderate/heavy drinking), tobacco use (current, former, never), e-cigarette use (current, former, never), and physical activity (0-150, $150<$ weekly minutes) for selected sociodemographic factors (e.g., age, birth gender, race/ethnicity, educational attainment, household income, marital status, health insurance, rurality of residence), clinical covariates (e.g., medical condition and psychological distress) (Table 3). We also performed weighted survey logistic regression for each health behavior to observe relationships between multiple unhealthy behaviors after adjusting associated factors found in Table 3 (Table 4). The statistical significance was determined at p-value < 0.05 and alpha $=0.05$. SAS 9.4 (SAS studio 3.8, Cary, NC, USA) was used for the analysis.

\section{Results}

\section{Cancer Survivor characteristics}

Nearly $84 \%$ of cancer survivors were 50 years or older (Table 1). Cancer survivors were more likely to be females (57\%), non-Hispanic Whites (79\%) than Black/African Americans (8.4\%), Asians (1.6\%), and others (2.1\%) and married (62\%). More than half of cancer survivors had some college education or more (65\%). Nearly half of cancer survivors reported their household income was less than $\$ 50,000(47 \%)$, and they had psychological distress (48\%), including little interest, hopelessness, nervousness, or worrying. Among those, the prevalence of each psychological distress was approximately $30-38 \%$. High blood pressure and arthritis were 2 most common co-morbidities among cancer survivors, $54.4 \%$ and $38.9 \%$, respectively. Half of cancer survivors have been diagnosed with cancer for 11 years or longer (47\%) while $14 \%$ were for less than 1 year. Skin (24.7\%), breast (13.2\%), and more than one cancer (16.6\%) were the most prevalent diagnoses in this study.

\section{Prevalence of unhealthy behaviors}

Most (75.1\%, SE 1.7) cancer survivors were light drinkers, yet $16.2 \%$ were heavy drinkers. Median (Inter quartile range, IQR) of average drinks per week was 0 (4) and mean (Standard Deviation, SD) was 3.41 (7.76). The prevalence of risky alcohol use (moderate/heavy drinking) was greater than the average in some sociodemographic groups, including cancer survivors who were males (30.6\%), were of non-Hispanic White race/ethnicity (28.3\%), had college graduate or more education $(36.5 \%)$, had household income $\$ 50,000$ or more $(31.3-35 \%)$, or in some clinical subgroups, including cancer survivors who were diagnosed with breast, prostate, skin cancer, or melanoma (25.7-32.3\%) (Table 2). The full prevalence information of cancer survivors' health behaviors can be found in supplementary file 1.

The majority (68.2\%, SE 1.6) of cancer survivors reported that they exercised for 150 minutes or less than weekly in this study. Median (IQR) of weekly minutes of moderate exercise was 90 (180) and mean (SD) was 159.42 (295.71). The prevalence of physical inactivity was greater than the average in cancer survivors who were of Black/African American race/ethnicity (81.8\%) or had high school or less education (73.8-86.3\%), had Tricare/VA/IHS (73.9\%). Cancer survivors with any co-morbidities examined in this study (71.6-78.1\%), had any type of psychological distress (73.4-78.5\%), or were diagnosed with breast, cervical, colon, melanoma, more than one, or other cancer $(69.1-78.6 \%)$ were more likely to be current e-cigarette smokers.

Fewer (11.8\%, SE 1.1) cancer survivors were current tobacco smokers than former (34.0\%, SE 1.3) or never tobacco smokers (54.3\%, SE 1.3). The prevalence of current tobacco smoking was greater than the average in cancer survivors who were $35-64$ years (15.1-18.7\%), were females (12.5\%), were of White (12.1\%) race/ethnicity, had high school graduate education (19.7\%) or were not married (15.3\%). Current tobacco smoking was higher among those who had lung disease (18.1\%), had depression (23.2\%), had any type of psychological distress (16.2-17.4\%), or were diagnosed with breast, cervical, colon, lung, more than one cancer, or melanoma (11.9-22.2\%).

Only 2.9\% (SE 0.6) were current e-cigarette users, while 89.4\% (SE 1.0) were never e-cigarette smokers. The prevalence of current e-cigarette smoking was greater than the average in cancer survivors who were $35-49$ years (6.7\%), females (3.7\%), of non-Hispanic White (3.5\%) or Hispanic (4.0\%) race/ethnicity, less educated, not married (4.5\%), or metropolitan residents (3.1\%). Current e-cigarette smoking was higher in those who had lung disease (6.6\%), had depression (7.0\%), had any type of psychological distress (5.5-6.5\%), or were diagnosed with breast, cervical, lung, or more than one cancer (3.8-14.6\%).

\section{Sociodemographic and clinical characteristics associated with unhealthy behaviors}

Males were 2 times more likely to be risky drinkers than females $(\mathrm{OR}=1.87,95 \% \mathrm{Cl}=1.10-3.16)($ Table 3$)$. Black/African Americans were less likely to be risky drinkers than non-Hispanic White cancer survivors ( $\mathrm{OR}=0.28,95 \% \mathrm{Cl}=0.11-0.74)$. Cancer survivors with private insurance were $2-3$ times more likely to be risky drinkers than those with Medicare/Medicaid. Physically active cancer survivors were 2 times more likely to have risky drinking behaviors $(0 R=1.74,95 \%$ $\mathrm{Cl}=1.15-2.63$ in $150<$ vs. $0-150$ minutes $)$. Former tobacco smokers were 1.5 times more likely to be risky drinkers $(\mathrm{OR}=1.58,95 \% \mathrm{Cl}=1.04-2.41$ in former vs. never smokers) (Table 4).

Males were more likely to use traditional tobacco (Table 3). Non-Hispanic Whites were 2 times more likely to be current smokers than Black/African American cancer survivors $(\mathrm{OR}=0.44,95 \% \mathrm{Cl}=0.21-0.93)$. Cancer survivors with less education were more likely to use tobacco currently than those with college graduate or more education. Metropolitan residents were more likely to smoke tobacco than micropolitan residents. Cancer survivors with lung disease or depression were 1.5-2 times likely to be current tobacco smokers than those without these diseases. Current/former e-cigarette smokers were much more likely to be current tobacco smokers than never e-cigarette users $(\mathrm{OR}=16.40,95 \% \mathrm{Cl}=3.29-81.89$ in current e-cigarette users, $\mathrm{OR}=10.19,95 \% \mathrm{Cl}=4.70-22.13$ in former vs. never e-cigarette users). Moderate/heavy drinkers were more likely to smoke tobacco than light drinkers $(\mathrm{OR}=1.75,95 \% \mathrm{Cl}=1.22-2.52)(\mathrm{Table} 4)$.

Younger cancer survivors, aged 18-49 years, were nearly 7 times more likely to use e-cigarette currently than survivors $\geq 75$ years (Table 2 ). Non-Hispanic Whites were 3-7 times more likely to be current e-cigarette users than Asians and Black/African Americans. Similar to the current tobacco smoking, cancer survivors with some college or less education were $2-4$ times more likely to be current e-cigarette users than those with more education $(\mathrm{OR}=2.15,95 \% \mathrm{Cl}=$ $1.09-4.23, \mathrm{OR}=3.08,95 \% \mathrm{Cl}=1.31-7.25, \mathrm{OR}=4.48,95 \% \mathrm{Cl}=1.01-19.82)$. Unmarried cancer survivors and metropolitan residents were $2-3$ times more likely 
to be current e-cigarette users than their counterparts, married or micropolitan residents, respectively. Cancer survivors with lung disease or depression were 2 times more likely to use e-cigarette than those without these health conditions. Current/former tobacco users were significantly more likely to use e-cigarette than never tobacco smokers ( $\mathrm{OR}=58.39,95 \% \mathrm{Cl}=18.46-184.66$ in current, $\mathrm{OR}=14.82,95 \% \mathrm{Cl}=4.76-46.20$ in former vs. never tobacco smokers) ( $\mathrm{Table} 4$ ).

Black/African Americans were 2 times more likely to be physically inactive than non-Hispanic White cancer survivors $(\mathrm{OR}=2.17,95 \% \mathrm{Cl}=1.05-4.48)$. Cancer survivors with some college education were more likely to be physically inactive than those with at least a college degree $(\mathrm{OR}=1.49,95 \% \mathrm{Cl}=1.01-2.20)$. Rural residents were 2 times more likely to be physically inactive than metropolitan residents. Publicly insured cancer survivors (Medicare, Medicaid, Tricare/VA/IHS) were 2 times less likely to exercise than those with private insurance. Cancer survivors with psychological distress (little interest) were 1.5 times more likely to be physically inactive than their counterparts. Moderate/heavy drinkers were less likely to be physically inactive than light drinkers (OR = $0.56,95 \% \mathrm{Cl}=0.38-0.84)$.

\section{Discussion}

Using nationally representative data, we identified sociodemographic and clinical subgroups of cancer survivors who have risky health behaviors, including males and those of non-Hispanic White and Black/African American race/ethnicity, without a college degree, not married, and with comorbidities or psychological distress. Overall, $24.9 \%$ of cancer survivors had risky alcohol use behaviors, $11.8 \%$ were current tobacco smokers, $2.9 \%$ currently used ecigarettes, and $68.2 \%$ did not meet recommended physical activity guidelines. Compared to a recent evaluation of health behaviors in 12,648 cancer survivors (2013-2017) [42], our estimates are similar for current tobacco/e-cigarette smoking, but higher for moderate/heavy drinking and lower for not meeting physical activity guidelines. Lastly, we found associations with risky health behaviors, including unhealthy alcohol use, tobacco and e-cigarette smoking, unhealthy behaviors that have been found to cluster together in the general U.S. population [60]. The findings of this study improve our understanding in cancer survivors' health behaviors and contribute to designing effective and efficient behavior modification interventions.

We observed that current tobacco smokers and e-cigarette users shared common sociodemographic and clinical characteristics. Cancer survivors who were non-Hispanic White, less educated, not married, metropolitan residents, and with lung disease or depression were more likely to use both tobacco and ecigarette. Our findings of an association between current tobacco use and e-cigarette use among cancer survivors are well aligned with the findings of multiple studies which e-cigarette use is associated with current tobacco smoking among the general population [61-64]. Thus, strategic cessation interventions to incorporate traditional tobacco smokers, e-cigarette smokers and dual smokers among cancer survivors will need to be considered. Additionally, the association of current drinking and current smoking that we observed in our study was found in multiple previous studies [41, 43, 65]. Moreover, current smoking status was related to physical inactivity among breast cancer patients, although the association was not significant in this study [5]. Overall, our findings suggest that interventions should consider addressing multiple risky health behaviors in cancer survivors.

We observed that cancer survivors with comorbidities and mental health conditions were more likely to smoke. Those with lung disease or depression were more likely to either tobacco or e-cigarette smoke. Moreover, cancer survivors with poor mental health (depression and little interest) were more likely to use ecigarette and exercise less. The associations of poor mental health status with unhealthy behaviors were reported previously; the odds of risky alcohol use were higher in breast cancer patients who were at-risk of depression [14] and the odds of e-cigarette smoking were higher in cancer survivors experiencing depression [66]. Comorbidities and mental distress are more common among cancer survivors than adults without an history of cancer [67, 68], highlighting the need to target these populations for smoking cessation and physical activity interventions to improve outcomes. In particular, moderate aerobic fitness and strength training have been found to be associated with improvements in breast cancer survivors' psychological state, including health-related quality of life, depression, anxiety and fatigue [4, 69-71].

Cancer survivors who were males or not married consistently presented unhealthy drinking and smoking behaviors. Our results are well aligned with previous reports that found male cancer survivors to be less likely successfully adopt or maintain healthy lifestyles [39]. Moreover, individuals who had a non-smoking spouse were more likely to attempt to quit or be successful in tobacco smoking [72,73]. Previous studies also report that marriage was a significant transitional moment in reduction of risky alcohol use and drinking problems became moderate after marriage [74]. Given these findings, incorporating spouses or partners in behavior change programs should be considered for cancer survivors [72].

In our study, cancer survivors with less than a college degree were more likely to smoke tobacco, use e-cigarettes and being physically inactive. The association of education with current tobacco smoking is consistent with smoking cessation attempts and sustained cessation in the general population [62, 75]. Specifically, those with more education were more likely to attempt to quit smoking as well as to maintain cessation status than their less educated counterparts $[62,75]$. Similarly, our findings of cancer survivors with lower education being more likely to be physical inactive are aligned with the previous studies among breast cancer survivors [5]. In addition, the associations of higher income with risky alcohol use observed in our study are comparable to a previous study that found higher income earners were more likely to be current or heavy drinkers, yet less likely to be tobacco smokers and physically inactive $[5,41]$.

We also observed that non-Hispanic White cancer survivors were more likely risky drinkers and current smokers (both tobacco and e-cigarette), and Black/African American cancer survivors were vulnerable to not meeting physical activity guidelines. The findings are consistent with a recent study using U.S. adults $(n=9,761)$ in the National Alcohol Survey [60]. In our study, nearly two thirds of cancer survivors did not meet the physical activity guidelines, highlighting the need to better understand the barriers to achieving physical activity goals. For example, a lack of social support for the physical activity promotion was addressed as a main barrier among Black/African American women [76].

Addressing unhealthy behaviors in cancer survivors is important for improving outcomes in this population. Specifically, risky alcohol consumption and current tobacco smoking were associated with increased all-cause and cancer specific [15-22, 77], while moderate physical activity was associated with improved all-cause and cancer specific mortality [29]. Although recent evidence showed that e-cigarette smoking could facilitate cancer progression and 
potentially exacerbate mental challenges, including depression, e-cigarette use is not often included in current tobacco cessation policies [24-27, 78]. Thus, efforts and resources to support risky health behavior modifications, including e-cigarette cessation, should target the most vulnerable subgroups of cancer survivors that we identified in this study.

This study has some limitations. First, our study used self-report based cross-sectional survey data. Although it is nationally representative and validated resource, it carries inherited weakness of subjectivity originated from self-reporting. Moreover, the small sample size of current and former e-cigarette users limited our ability to identify high-risk subgroups. Further investigation with larger sample size will be necessary to understand the factors associated with ecigarette smoking in cancer survivors. However, we are among the first studies to examine e-cigarette use among cancer survivors, reporting the prevalence and the associated factors of e-cigarette use. Lastly, our study cannot show the temporality of associations between unhealthy behaviors with sociodemographic and clinical characteristics. Hence, our findings are unable to take into consideration changes in health behaviors over time within cancer survivors. Despite these limitations, the strengths of the present study include the comprehensive investigation of unhealthy behaviors by sociodemographic and clinical characteristics among cancer survivors diagnosed with all types of cancer.

\section{Conclusion}

Our findings suggest that cancer subgroups who are males, non-Hispanic Whites or Black/African American, without a college degree, not married, and with comorbidities or psychological distress were more likely to have risky health behaviors. Furthermore, we observed clusters of risky health behaviors, particularly tobacco smoking, e-cigarette use and risky drinking. Our findings inform clinicians and program and policy makers of the subgroups of cancer survivors to target for health behavior interventions.

\section{Declarations}

\section{Funding}

The authors declare that no funds, grants, or other support were received for the preparation of this manuscript.

\section{Competing Interests}

The authors have no relevant financial or non-financial interests to disclose.

\section{Author Contributions}

Jiyeong Kim conceptualized and designed the study. Jiyeong Kim prepared the materials and primarily analyzed the data, and Theresa $\mathrm{H}$ Keegan contributed to data analysis and result interpretation. Jiyeong Kim drafted the first manuscript, and Jiyeong Kim and Theresa H Keegan revised the previous versions of the manuscript together. All authors read and approved the final manuscript.

\section{Data Availability}

The data for this study is publicly available at https://hints.cancer.gov/data/download-data.aspx

\section{Ethics Approval}

This study was a secondary data analysis. Human subject was not involved, and identifiable information was not included. Thus, this was deemed exempt for review by the Institutional Review Board at University of California, Davis.

\section{Consent to participate}

Not applicable.

\section{Consent to publish}

The authors transfer to the publisher the sole and exclusive publication rights.

\section{References}

1. Cancer Statistics - National Cancer Institute. https://www.cancer.gov/about-cancer/understanding/statistics. Accessed 19 Jan 2022.

2. Berry DA, Cronin KA, Plevritis SK, Fryback DG, Clarke L, Zelen M, et al. Effect of screening and adjuvant therapy on mortality from breast cancer. N Engl J Med. 2005;353:1784-92. doi:10.1056/NEJMOA050518.

3. Thrift AP, Nagle CM, Fahey PP, Russell A, Smithers BM, Watson DI, et al. The influence of prediagnostic demographic and lifestyle factors on esophageal squamous cell carcinoma survival. Int J cancer. 2012;131. doi:10.1002/IJC.27420.

4. Ligibel J. Lifestyle factors in cancer survivorship. J Clin Oncol. 2012;30:3697-704. doi:10.1200/JC0.2012.42.0638.

5. Di Meglio A, Gbenou AS, Martin E, Pistilli B, Ligibel JA, Crane TE, et al. Unhealthy behaviors after breast cancer: Capitalizing on a teachable moment to promote lifestyle improvements. Cancer. 2021;127:2774-87. doi:10.1002/CNCR.33565

6. Barrault-Couchouron M, Béracochéa M, Dorval M, Allafort V, Barthélémy V, Garguil V, et al. [Tobacco and alcohol consumption in women treated for breast cancer in a department of surgical oncology: Frequent behaviours to consider]. Bull Cancer. 2021. doi:10.1016/J.BULCAN.2021.07.005. 
7. Doyle C, Kushi LH, Byers T, Courneya KS, Demark-Wahnefried W, Grant B, et al. Nutrition and physical activity during and after cancer treatment: an American Cancer Society guide for informed choices. CA Cancer J Clin. 2006;56:323-53. doi:10.3322/CANJCLIN.56.6.323.

8. Pelucchi C, Tramacere I, Boffetta P, Negri E, Vecchia C. La. Alcohol consumption and cancer risk. Nutr Cancer. 2011;63:983-90. doi:10.1080/01635581.2011.596642.

9. MS C, TS M, WH K. W Y, B Z. Knowledge, perceptions, and attitudes of Hong Kong Chinese women on screening mammography and early breast cancer management. Breast J. 2005;11:52-6. doi:10.1111/J.1075-122X.2005.21480.X.

10. Kwan ML, Kushi LH, Weltzien E, Tam EK, Castillo A, Sweeney C, et al. Alcohol consumption and breast cancer recurrence and survival among women with early-stage breast cancer: the life after cancer epidemiology study. J Clin Oncol. 2010;28:4410-6. doi:10.1200/JC0.2010.29.2730.

11. Simapivapan P, Boltong A, Hodge A. To what extent is alcohol consumption associated with breast cancer recurrence and second primary breast cancer?: A systematic review. Cancer Treat Rev. 2016;50:155-67. doi:10.1016/J.CTRV.2016.09.010.

12. Patterson RE, Cadmus LA, Emond JA, Pierce JP. Physical activity, diet, adiposity and female breast cancer prognosis: a review of the epidemiologic literature. Maturitas. 2010;66:5-15. doi:10.1016/J.MATURITAS.2010.01.004.

13. Dal Maso L, Zucchetto A, Talamini R, Serraino D, Stocco CF, Vercelli M, et al. Effect of obesity and other lifestyle factors on mortality in women with breast cancer. Int J cancer. 2008;123:2188-94. doi:10.1002/IJC.23747.

14. Flatt SW, Thomson CA, Gold EB, Natarajan L, Rock CL, Al-Delaimy WK, et al. Low to moderate alcohol intake is not associated with increased mortality after breast cancer. Cancer Epidemiol Biomarkers Prev. 2010;19:681-8. doi:10.1158/1055-9965.EPI-09-0927.

15. Jha P, Ramasundarahettige C, Landsman V, Rostron B, Thun M, Anderson RN, et al. 21st-century hazards of smoking and benefits of cessation in the United States. N Engl J Med. 2013;368:341-50. doi:10.1056/NEJMSA1211128.

16. Capelletto E, Passiglia F, Ferraresi F, Vallone S, Novello S. Improving lung cancer outcomes through smoking cessation: the Women Against Lung Cancer in Europe (WALCE) experience. J Thorac Dis. 2020;12:3877. doi:10.21037/JTD.2020.03.76.

17. Holmes MD, Murin S, Chen WY, Kroenke CH, Spiegelman D, Colditz GA. Smoking and survival after breast cancer diagnosis. Int J cancer. 2007;120:26727. doi:10.1002/IJC.22575.

18. Seibold P, Vrieling A, Heinz J, Obi N, Sinn HP, Flesch-Janys D, et al. Pre-diagnostic smoking behaviour and poorer prognosis in a German breast cancer patient cohort - Differential effects by tumour subtype, NAT2 status, BMI and alcohol intake. Cancer Epidemiol. 2014;38:419-26. doi:10.1016/J.CANEP.2014.05.006.

19. Tominaga K, Andow J, Koyama Y, Numao S, Kurokawa E, Ojima M, et al. Family environment, hobbies and habits as psychosocial predictors of survival for surgically treated patients with breast cancer. Jpn J Clin Oncol. 1998;28:36-41. doi:10.1093/JJCO/28.1.36.

20. Hellmann SS, Thygesen LC, Tolstrup JS, Grønbæk M. Modifiable risk factors and survival in women diagnosed with primary breast cancer: results from a prospective cohort study. Eur J Cancer Prev. 2010;19:366-73. doi:10.1097/CEJ.0B013E32833B4828.

21. Wang K, Li F, Zhang X, Li Z, Li H. Smoking increases risks of all-cause and breast cancer specific mortality in breast cancer individuals: a dose-response meta-analysis of prospective cohort studies involving 39725 breast cancer cases. Oncotarget. 2016;7:83134-47. doi:10.18632/ONCOTARGET.13366.

22. Passarelli MN, Newcomb PA, Hampton JM, Trentham-Dietz A, Titus LJ, Egan KM, et al. Cigarette Smoking Before and After Breast Cancer Diagnosis: Mortality From Breast Cancer and Smoking-Related Diseases. J Clin Oncol. 2016;34:1315-22. doi:10.1200/JC0.2015.63.9328.

23. Duan W, Li S, Meng X, Sun Y, Jia C. Smoking and survival of breast cancer patients: A meta-analysis of cohort studies. Breast. 2017;33:117-24. doi:10.1016/J.BREAST.2017.03.012.

24. Mravec B, Tibensky M, Horvathova L, Babal P. E-Cigarettes and Cancer Risk. Cancer Prev Res. 2020;13:137-44. doi:10.1158/1940-6207.CAPR-19-0346.

25. Canistro D, Vivarelli F, Cirillo S, reports CBM-S. 2017 undefined. E-cigarettes induce toxicological effects that can raise the cancer risk. nature.com. https://www.nature.com/articles/s41598-017-02317-8. Accessed 12 Feb 2022.

26. Staudt MR, Salit J, Kaner RJ, Hollmann C, Crystal RG. Altered lung biology of healthy never smokers following acute inhalation of E-cigarettes. Respir Res. 2018;19. doi:10.1186/S12931-018-0778-Z.

27. Schaal CM, Bora-Singhal N, Kumar DM, Chellappan SP. Regulation of Sox2 and stemness by nicotine and electronic-cigarettes in non-small cell lung cancer 06 Biological Sciences 0601 Biochemistry and Cell Biology 11 Medical and Health Sciences 1112 Oncology and Carcinogenesis. Mol Cancer. 2018;17.

28. Salloum RG, Getz KR, Tan ASL, Carter-Harris L, Young-Wolff KC, George TJ, et al. Use of Electronic Cigarettes Among Cancer Survivors in the U.S. Am J Prev Med. 2016;51:762-6. doi:10.1016/J.AMEPRE.2016.04.015.

29. Friedenreich CM, Stone CR, Cheung WY, Hayes SC. Physical Activity and Mortality in Cancer Survivors: A Systematic Review and Meta-Analysis. JNCI cancer Spectr. 2019;4. doi:10.1093/JNCICS/PKZ080.

30. Markes M, Brockow T, Resch KL. Exercise for women receiving adjuvant therapy for breast cancer. Cochrane database Syst Rev. 2006. doi:10.1002/14651858.CD005001.PUB2.

31. Meyerhardt JA, Giovannucci EL, Holmes MD, Chan AT, Chan JA, Colditz GA, et al. Physical activity and survival after colorectal cancer diagnosis. J Clin Oncol. 2006;24:3527-34.

32. Irwin ML, Smith AW, McTiernan A, Ballard-Barbash R, Cronin K, Gilliland FD, et al. Influence of pre- and postdiagnosis physical activity on mortality in breast cancer survivors: The health, eating, activity, and lifestyle study. J Clin Oncol. 2008;26:3958-64.

33. Rowland J, Gallicchio L. ... MM-JJ of the, 2019 undefined. Survivorship science at the NIH: lessons learned from grants funded in fiscal year 2016. academic.oup.com. https://academic.oup.com/jnci/article-abstract/111/2/109/5290236. Accessed 19 Jan 2022. 
34. Song M, oncology EG-J. 2016 undefined. Preventable incidence and mortality of carcinoma associated with lifestyle factors among white adults in the United States. jamanetwork.com. https://jamanetwork.com/journals/jamaoncology/article-abstract/2522371. Accessed 19 Jan 2022.

35. Rock CL, Doyle C, Demark-Wahnefried W, Meyerhardt J, Courneya KS, Schwartz AL, et al. Nutrition and physical activity guidelines for cancer survivors. CA Cancer J Clin. 2012;62:242-74. doi:10.3322/CAAC.21142.

36. Krist AH, Davidson KW, Mangione CM, Barry MJ, Cabana M, Caughey AB, et al. Interventions for Tobacco Smoking Cessation in Adults, Including Pregnant Persons: US Preventive Services Task Force Recommendation Statement. JAMA. 2021;325:265-79.

37. Healthy Living After Cancer | Cancer.Net. https://www.cancer.net/survivorship/healthy-living/healthy-living-after-cancer. Accessed 19 Jan 2022.

38. Kim M, Choi KS, Suh M, Jun JK, Chuck KW, Park B. Risky Lifestyle Behaviors among Gastric Cancer Survivors Compared with Matched Non-cancer Controls: Results from Baseline Result of Community Based Cohort Study. Cancer Res Treat. 2018;50:738-47. doi:10.4143/CRT.2017.129.

39. Demark-Wahnefried W, Aziz NM, Rowland JH, Pinto BM. Riding the crest of the teachable moment: promoting long-term health after the diagnosis of cancer. J Clin Oncol. 2005;23:5814-30. doi:10.1200/JC0.2005.01.230.

40. Blanchard CM, Courneya KS, Stein K. Cancer survivors' adherence to lifestyle behavior recommendations and associations with health-related quality of life: Results from the American Cancer Society's SCS-II. J Clin Oncol. 2008;26:2198-204.

41. Park B, Kong SY, Kim J, Kim Y, Park IH, Jung SY, et al. Health Behaviors of Cancer Survivors in Nationwide Cross-Sectional Survey in Korea: Higher Alcohol Drinking, Lower Smoking, and Physical Inactivity Pattern in Survivors with Higher Household Income. Med (Baltim). $2015 ; 94$. doi:10.1097/MD.0000000000001214

42. Arem H, Mama SK, Duan X, Rowland JH, Bellizzi KM, Ehlers DK. Prevalence of Healthy Behaviors among Cancer Survivors in the United States: How Far Have We Come? Cancer Epidemiol Prev Biomarkers. 2020;29:1179-87. doi:10.1158/1055-9965.EPI-19-1318.

43. Yoon J, Park B. Factors Associated with Health Behaviors in Thyroid Cancer Survivors. J cancer Prev. 2020;25:173-80. doi:10.15430/JCP.2020.25.3.173.

44. Ostrof JS, Jacobsen PB, Moadel AB, Spiro RH, Shah JP, Strong EW, et al. Prevalence and Predictors of Continued Tobacco Use after Treatment of Patients with Head and Neck Cancer.

45. Ark W, Vander, DiNardo LJ, Oliver DS. Factors affecting smoking cessation in patients with head and neck cancer. Laryngoscope. 1997;107:888-92. doi:10.1097/00005537-199707000-00010.

46. Allison PJ. Factors associated with smoking and alcohol consumption following treatment for head and neck cancer. Oral Oncol. 2001;37:513-20. doi:10.1016/S1368-8375(01)00015-X.

47. Patterson RE, Neuhouser ML, Hedderson MM, Schwartz SM, Standish LJ, Bowen DJ. Changes in diet, physical activity, and supplement use among adults diagnosed with cancer. J Am Diet Assoc. 2003;103:323-8. doi:10.1053/JADA.2003.50045.

48. Khadanga S, Lakoski SG, Hart V, Sprague BL, Ba Y, Hampton JM, et al. Partnership Status and Socioeconomic Factors in Relation to Health Behavior Changes after a Diagnosis of Ductal Carcinoma In Situ. Cancer Epidemiol Biomarkers Prev. 2016;25:76-82. doi:10.1158/1055-9965.EPI-15-0726.

49. Survey Instruments | HINTS. https://hints.cancer.gov/data/survey-instruments.aspx. Accessed 23 Aug 2021.

50. von E E, DG A, SJ ME, PC P. G, JP V. The Strengthening the Reporting of Observational Studies in Epidemiology (STROBE) statement: guidelines for reporting observational studies. Ann Intern Med. 2007;147:573-7. doi:10.7326/0003-4819-147-8-200710160-00010.

51. Westat. Health Information National Trends Survey 5 (HINTS 5) Cycle 4 Methodology Report. 2020.

52. Definition of survivor - NCI Dictionary of Cancer Terms - National Cancer Institute. https://www.cancer.gov/publications/dictionaries/cancerterms/def/survivor. Accessed 20 Jan 2022.

53. NHIS - Adult Alcohol Use - Glossary. https://www.cdc.gov/nchs/nhis/alcohol/alcohol_glossary.htm. Accessed 20 Jan 2022.

54. Bagnardi V, Rota M, Botteri E, Tramacere I, Islami F, Fedirko V, et al. Alcohol consumption and site-specific cancer risk: a comprehensive dose-response meta-analysis. Br J Cancer. 2015;112:580-93. doi:10.1038/BJC.2014.579.

55. Cao Y, Willett WC, Rimm EB, Stampfer MJ, Giovannucci EL. Light to moderate intake of alcohol, drinking patterns, and risk of cancer: results from two prospective US cohort studies. BMJ. 2015;351. doi:10.1136/BMJ.H4238.

56. Scientific Report | health.gov. https://health.gov/our-work/nutrition-physical-activity/physical-activity-guidelines/current-guidelines/scientific-report. Accessed 20 Jan 2022.

57. Odphp. 2008 Physical Activity Guidelines for Americans. www.health.gov/paguidelines. Accessed 20 Jan 2022.

58. Social Determinants of Health. - Healthy People 2030 | health.gov. https://health.gov/healthypeople/objectives-and-data/social-determinants-health. Accessed 23 Aug 2021.

59. Cohen SA, Kunicki ZJ, Nash CC, Drohan MM, Greaney ML. Rural-Urban Differences in Caregiver Burden Due to the COVID-19 Pandemic among a National Sample of Informal Caregivers. Gerontol Geriatr Med. 2021;7. doi:10.1177/23337214211025124.

60. Cook WK, Kerr WC, Karriker-Jaffe KJ, Li L, Lui CK, Greenfield TK. Racial/Ethnic Variations in Clustered Risk Behaviors in the U.S. Am J Prev Med. 2020;58:e21. doi:10.1016/J.AMEPRE.2019.08.020.

61. Unger JB, Soto DW, Leventhal A. E-cigarette use and subsequent cigarette and marijuana use among Hispanic young adults. Drug Alcohol Depend. 2016;163:261-4. doi:10.1016/J.DRUGALCDEP.2016.04.027

62. Soneji S, Barrington-Trimis JL, Wills TA, Leventhal AM, Unger JB, Gibson LA, et al. Association Between Initial Use of e-Cigarettes and Subsequent Cigarette Smoking Among Adolescents and Young Adults: A Systematic Review and Meta-analysis. JAMA Pediatr. 2017;171:788-97.

doi:10.1001/JAMAPEDIATRICS.2017.1488. 
63. Sciences NA of, Engineering undefined, and undefined. Public health consequences of e-cigarettes. 2018. https://books.google.com/books? $\mathrm{hl}=$ =n\&lr=\&id=jQhgDwAAQBAJ\&oi=fnd\&pg=PR1\&ots=owdCXKYbVC\&sig=FdJ-sz8KbBIGz-uUNDj9n0uTHPM. Accessed 31 Jan 2022.

64. Hornik R, Gibson L. Evidence for a plateau in the... Google Scholar. https://scholar.google.com/scholar? $\mathrm{hl}=\mathrm{en} \& \mathrm{q}=\% 0 \mathrm{AH}$ ornik+R\%2C+Gibson+L.+Evidence+for+a+plateau+in+the+use+of+e-cigarettes+since+mid2014\%3A+comparisons+with+combustible+cigarette+use\%3A+time+series+results+from+a+nationally+representative+survey+of+1325+year+olds.+Poster+presented+at+the+Annual+Meeting+of+the+Society+for+Research+on+Nicotine+\%26+Tobacco\%2C+March+2016\%2C+Chicago\%2 Accessed 2 Feb 2022.

65. Hamajima N, Hirose K, Tajima K, Rohan T, Calle EE, Heath CW, et al. Alcohol, tobacco and breast cancer-collaborative reanalysis of individual data from 53 epidemiological studies, including 58,515 women with breast cancer and 95,067 women without the disease. Br J Cancer. 2002;87:1234-45. doi:10.1038/SJ.BJC.6600596.

66. Antwi GO, Darson ; Rhodes L. Association between e-cigarette use and depression in US cancer survivors: a cross-sectional study. J Cancer Surviv 2022. 2022;:1-9. doi:10.1007/S11764-022-01176-1.

67. Mitchell AJ, Ferguson DW, Gill J, Paul J, Symonds P. Depression and anxiety in long-term cancer survivors compared with spouses and healthy controls: a systematic review and meta-analysis. Lancet Oncol. 2013;14:721-32. doi:10.1016/S1470-2045(13)70244-4.

68. Ogle KS, Swanson GM, Woods N, Azzouz F, Ogle S. Cancer and Comorbidity Redefining Chronic Diseases. 2000.

69. McNeely ML, Campbell KL, Rowe BH, Klassen TP, Mackey JR, Courneya KS. Effects of exercise on breast cancer patients and survivors: a systematic review and meta-analysis. CMAJ. 2006;175:34-41. doi:10.1503/CMAJ.051073.

70. Schmitz KH, Courneya KS, Matthews C, Demark-Wahnefried W, Galvão DA, Pinto BM, et al. American College of Sports Medicine roundtable on exercise guidelines for cancer survivors. Med Sci Sports Exerc. 2010;42:1409-26. doi:10.1249/MSS.0B013E3181E0C112.

71. Demark-Wahnefried W, Schmitz KH, Alfano CM, Bail JR, Goodwin PJ, Thomson CA, et al. Weight management and physical activity throughout the cancer care continuum. CA Cancer J Clin. 2018;68:64-89. doi:10.3322/CAAC.21441.

72. Jackson SE, Steptoe A, Wardle J. The influence of partner's behavior on health behavior change: the English Longitudinal Study of Ageing. JAMA Intern Med. 2015;175:385-92. doi:10.1001/JAMAINTERNMED.2014.7554.

73. Homish GG, Leonard KE. Spousal influence on smoking behaviors in a US community sample of newly married couples. Soc Sci Med. $2005 ; 61: 2557-67$. doi:10.1016/J.SOCSCIMED.2005.05.005.

74. Miller-Tutzauer C, Leonard KE, Windle M. Marriage and alcohol use: a longitudinal study of "maturing out.". J Stud Alcohol. 1991;52:434-40. doi:10.15288/JSA.1991.52.434.

75. Leventhal AM, Dai H, Higgins ST. Smoking Cessation Prevalence and Inequalities in the United States: 2014-2019. J Natl Cancer Inst. 2021. doi:10.1093/JNCl/DJAB208.

76. Joseph RP, Ainsworth BE, Keller C, Dodgson JE. Barriers to Physical Activity Among African American Women: An Integrative Review of the Literature. Women Health. 2015;55:679-99. doi:10.1080/03630242.2015.1039184.

77. Allemani C, Berrino F, Krogh V, Sieri S, Pupa SM, Tagliabue E, et al. Do pre-diagnostic drinking habits influence breast cancer survival? Tumori. 2011;97:142-8. doi:10.1700/667.7774.

78. Saeed OB, Chavan B, Haile ZT. Association Between E-cigarette Use and Depression in US Adults. J Addict Med. 2020;14:393-400. doi:10.1097/ADM.0000000000000604.

\section{Tables}

\section{Table 1. Sociodemographic and Clinical Characteristics of Cancer Population}




\begin{tabular}{|c|c|c|c|}
\hline & Frequency (n) & $\begin{array}{l}\text { Weighted } \\
\text { Percentage (\%) }\end{array}$ & $\begin{array}{l}\text { Standard } \\
\text { Error (SE) }\end{array}$ \\
\hline \multicolumn{4}{|c|}{ Sociodemographic Characteristics } \\
\hline \multicolumn{4}{|l|}{ Age (years) } \\
\hline $18-34$ & 36 & 4.2 & 1.2 \\
\hline $35-49$ & 164 & 12.0 & 1.2 \\
\hline $50-64$ & 727 & 33.3 & 1.5 \\
\hline $65-74$ & 832 & 25.4 & 1.2 \\
\hline$\geq 75$ & 765 & 25.1 & 1.0 \\
\hline \multicolumn{4}{|l|}{ Gender } \\
\hline Male & 1065 & 43.1 & 1.5 \\
\hline Female & 1487 & 57.0 & 1.5 \\
\hline \multicolumn{4}{|l|}{ Race/Ethnicity } \\
\hline White & 1759 & 79.3 & 1.4 \\
\hline Black/African American & 224 & 8.4 & 1.1 \\
\hline Hispanic & 184 & 8.6 & 1.1 \\
\hline Asian & 44 & 1.6 & 0.3 \\
\hline Others & 70 & 2.1 & 0.4 \\
\hline \multicolumn{4}{|l|}{ Education } \\
\hline Less Than High School & 152 & 6.8 & 1.0 \\
\hline High School Graduate & 535 & 27.2 & 1.4 \\
\hline Some College & 780 & 37.8 & 1.5 \\
\hline College Graduate or More & 1058 & 28.1 & 1.2 \\
\hline \multicolumn{4}{|l|}{ Household income } \\
\hline$<\$ 20,000$ & 414 & 16.9 & 1.4 \\
\hline$\$ 20,000$ to $<\$ 35,000$ & 362 & 14.5 & 1.1 \\
\hline$\$ 35,000$ to $<\$ 50,000$ & 324 & 15.7 & 1.6 \\
\hline$\$ 50,000$ to $<\$ 75,000$ & 415 & 18.8 & 1.4 \\
\hline$\geq \$ 75,000$ & 727 & 34.1 & 1.6 \\
\hline \multicolumn{4}{|l|}{ Marital status } \\
\hline Married & 1310 & 61.7 & 1.5 \\
\hline Not married & 1215 & 38.3 & 1.5 \\
\hline \multicolumn{4}{|l|}{ Employment } \\
\hline Employed & 507 & 35.9 & 1.8 \\
\hline Not employed & 1163 & 64.1 & 1.8 \\
\hline \multicolumn{4}{|l|}{ Area: Rurality } \\
\hline Metropolitan & 2186 & 81.9 & 1.1 \\
\hline Micropolitan & 212 & 10.3 & 0.9 \\
\hline Small Town & 98 & 3.9 & 0.6 \\
\hline Rural & 83 & 3.9 & 0.5 \\
\hline \multicolumn{4}{|l|}{ Health insurance } \\
\hline Employment and Private & 654 & 35.1 & 1.6 \\
\hline Medicare & 1165 & 38.9 & 1.4 \\
\hline Medicaid & 300 & 15.6 & 1.4 \\
\hline
\end{tabular}

Page 10/15 


\begin{tabular}{|c|c|c|c|}
\hline Tricare, VA, IHS & 316 & 10.4 & 0.8 \\
\hline \multicolumn{4}{|l|}{ Clinical Characteristics } \\
\hline \multicolumn{4}{|l|}{ Medical condition } \\
\hline Diabetes & 693 & 24.3 & 1.4 \\
\hline High blood pressure & 1492 & 54.4 & 1.5 \\
\hline Heart disease & 409 & 15.1 & 1.1 \\
\hline Lung disease & 452 & 16.6 & 1.0 \\
\hline Arthritis & 487 & 38.9 & 2.1 \\
\hline Depression & 579 & 22.7 & 1.2 \\
\hline \multicolumn{4}{|l|}{ Psychological distress } \\
\hline Little Interest & 850 & 35.8 & 1.5 \\
\hline Hopelessness & 712 & 30.0 & 1.5 \\
\hline Nervousness & 868 & 37.8 & 1.6 \\
\hline Worrying & 753 & 32.8 & 1.6 \\
\hline \multicolumn{4}{|l|}{ Time since diagnosis } \\
\hline$<1$ year & 304 & 13.9 & 1.2 \\
\hline $2-5$ years & 513 & 20.6 & 1.2 \\
\hline $6-10$ years & 460 & 18.5 & 1.2 \\
\hline$\geq 11$ years & 1148 & 47.0 & 1.6 \\
\hline \multicolumn{4}{|l|}{ Cancer type } \\
\hline Breast cancer & 370 & 13.2 & 1.0 \\
\hline Cervical cancer & 132 & 6.8 & 0.9 \\
\hline Prostate cancer & 234 & 6.5 & 0.6 \\
\hline Colon cancer & 106 & 3.9 & 0.5 \\
\hline Skin cancer & 635 & 24.7 & 1.3 \\
\hline Melanoma & 118 & 5.0 & 0.7 \\
\hline Lung cancer & 49 & 1.8 & 0.4 \\
\hline More than one cancer & 438 & 16.6 & 1.0 \\
\hline Other cancer & 453 & 21.4 & 1.6 \\
\hline
\end{tabular}

Abbreviations. VA: Veterans Affairs; IHS: Indian Health Services.

Table 2. Prevalence of Unhealthy Behaviors by Sociodemographic and Clinical Factors Among Cancer Survivors ${ }^{+}$ 


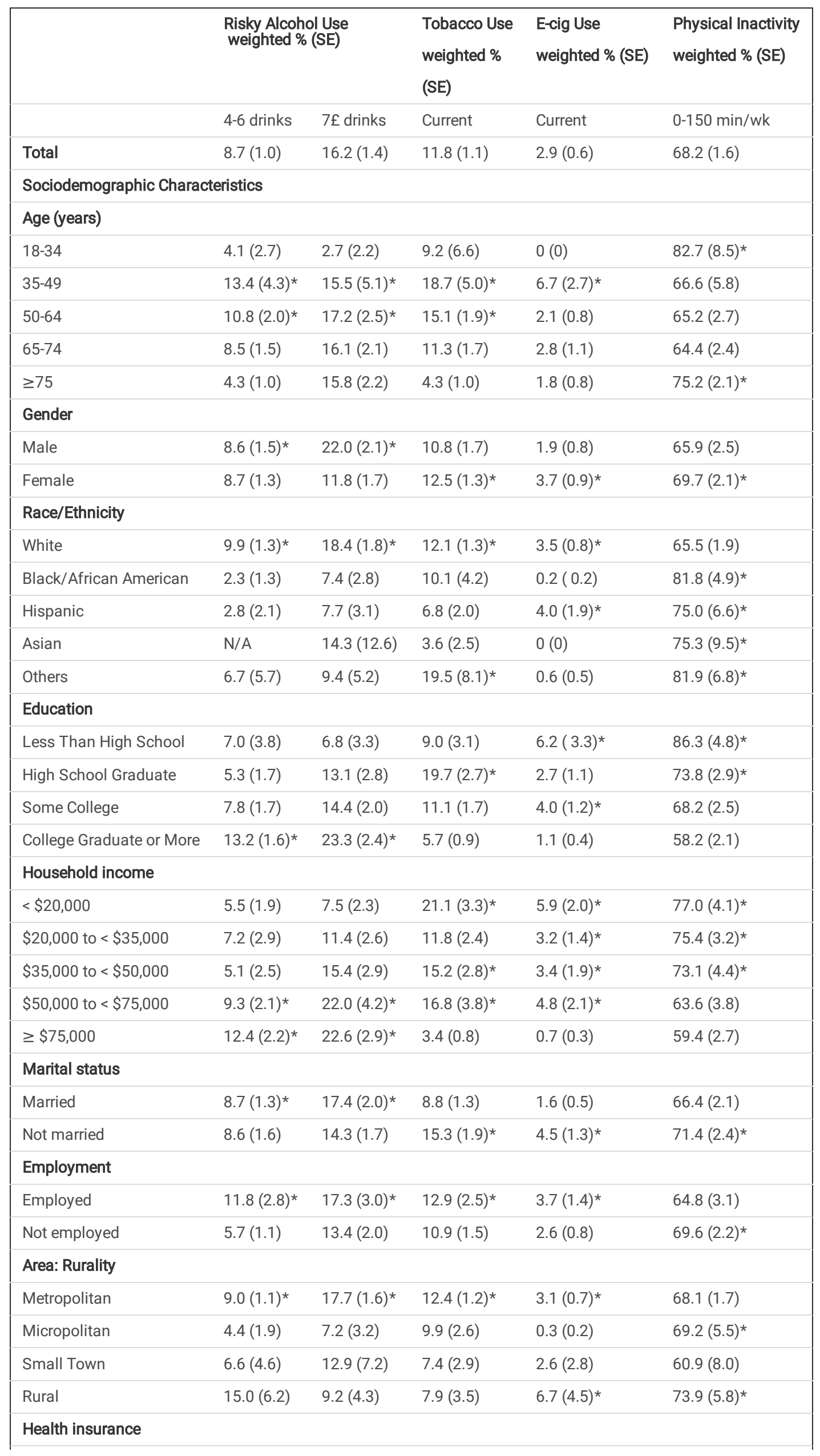

Page 12/15 


\begin{tabular}{|c|c|c|c|c|c|}
\hline Employment and Private & $14.0(2.2)^{\star}$ & $19.1(2.8)^{\star}$ & $13.2(2.3)^{\star}$ & $2.6(1.1)$ & $58.6(3.0)$ \\
\hline Medicare & $7.7(1.2)$ & $15.3(1.8)$ & $7.1(1.0)$ & $1.7(0.6)$ & $69.8(1.9)^{*}$ \\
\hline Medicaid & $4.6(2.0)$ & $6.0(2.3)$ & $17.0(3.0)^{\star}$ & $6.9(2.4)^{\star}$ & $81.2(3.5)^{\star}$ \\
\hline Tricare, VA, IHS & $3.0(1.3)$ & $21.1(4.2)$ & $9.3(3.4)$ & $1.2(0.6)$ & $73.9(3.3)^{*}$ \\
\hline \multicolumn{6}{|l|}{ Clinical Characteristics } \\
\hline \multicolumn{6}{|l|}{ Medical condition } \\
\hline Diabetes & $5.1(2.1)$ & $9.4(1.8)$ & $10.6(1.6)$ & $3.1(0.9)^{\star}$ & $73.2(2.9)^{\star}$ \\
\hline High blood pressure & $6.5(1.1)$ & $16.9(1.8)$ & $11.1(1.3)$ & $2.7(0.7)$ & $71.6(2.0)^{\star}$ \\
\hline Heart disease & $5.9(1.7)$ & $15.5(3.5)$ & $11.3(2.5)$ & $1.9(0.9)$ & $78.1(3.3)^{*}$ \\
\hline Lung disease & $7.0(1.9)$ & $10.0(2.7)$ & $18.1(2.7)^{\star}$ & $6.6(2.4)^{\star}$ & $77.4(3.0)^{*}$ \\
\hline Arthritis & $2.7(1.1)$ & $13.7(3.4)$ & $9.5(1.7)$ & $3.0(1.3)^{\star}$ & $73.6(2.9)$ * \\
\hline Depression & $8.7(2.1)$ & $13.0(2.4)$ & $23.2(2.9)^{*}$ & $7.0(1.7)^{\star}$ & $76.7(2.5)^{\star}$ \\
\hline \multicolumn{6}{|l|}{ Psychological distress } \\
\hline Little Interest & $8.0(1.9)$ & $15.2(2.8)$ & $16.7(2.1)^{\star}$ & $5.5(1.4)^{\star}$ & $78.5(2.6)^{*}$ \\
\hline Hopelessness & $9.8(2.1)^{\star}$ & $16.7(3.2)^{\star}$ & $17.4(2.3)^{\star}$ & $5.8(1.5)^{\star}$ & $76.7(2.8) *$ \\
\hline Nervousness & $9.4(2.0)^{\star}$ & $16.3(2.7)^{\star}$ & $16.4(2.0)^{\star}$ & $6.0(1.4)^{\star}$ & $74.2(2.6)^{*}$ \\
\hline Worrying & $9.4(2.1)$ & $15.0(2.8)$ & $16.2(2.3)^{\star}$ & $6.5(1.7)^{\star}$ & $73.4(2.9)$ * \\
\hline \multicolumn{6}{|l|}{ Time since diagnosis } \\
\hline$<1$ year & $5.6(2.0)$ & $9.7(2.8)$ & $6.2(1.4)$ & $2.3(1.1)$ & $71.8(4.2)^{*}$ \\
\hline $2-5$ years & $7.8(2.2)^{\star}$ & $21.9(3.5)^{*}$ & $13.9(2.9)^{*}$ & $3.0(1.4)^{\star}$ & $67.1(3.0)$ \\
\hline $6-10$ years & $13.3(2.6)^{\star}$ & $16.0(3.6)^{*}$ & $11.9(2.7)^{\star}$ & $3.1(1.5)^{\star}$ & $64.7(3.5)$ \\
\hline$\geq 11$ years & $8.5(1.5)$ & $15.2(1.8)$ & $11.8(1.5)$ & $2.8(0.9)$ & $69.4(2.3)^{*}$ \\
\hline \multicolumn{6}{|l|}{ Cancer type } \\
\hline Breast cancer & $8.6(2.3)^{\star}$ & $17.1(4.8)^{*}$ & $13.9(3.2)^{*}$ & $3.9(1.6)^{*}$ & $69.7(4.0)^{*}$ \\
\hline Cervical cancer & $16.3(6.7)$ & $5.0(2.4)$ & $20.3(5.3)^{\star}$ & $4.0(2.4)^{\star}$ & $71.4(7.0)^{*}$ \\
\hline Prostate cancer & $5.4(2.2)^{\star}$ & $24.5(5.1)^{\star}$ & $9.1(3.1)$ & $2.7(2.7)$ & $64.7(4.9)$ \\
\hline Colon cancer & $3.8(2.2)$ & $11.9(4.6)$ & $14.5(8.0)^{\star}$ & $7.3(7.5)$ & $75.5(8.1)^{*}$ \\
\hline Skin cancer & $9.7(1.9)^{\star}$ & $21.8(2.6)^{*}$ & $7.8(1.7)$ & $1.1(0.4)$ & $62.3(2.8)$ \\
\hline Melanoma & $5.7(2.5)^{*}$ & $26.6(8.8)^{\star}$ & $13.5(6.7)^{*}$ & $1.2(0.9)$ & $78.6(5.4)^{\star}$ \\
\hline Lung cancer & $4.4(4.0)$ & $16.0(9.6)$ & $22.2(12.0)^{\star}$ & $14.6(11.9)^{\star}$ & $67.9(9.6)$ \\
\hline More than one cancer & $8.4(2.4)$ & $16.2(3.0)$ & $11.9(2.6)^{\star}$ & $3.8(1.6)^{\star}$ & $70.4(3.1)^{*}$ \\
\hline Other cancer & $8.7(2.2)$ & $8.8(2.0)$ & $11.8(2.2)$ & $2.2(0.8)$ & $69.1(4.0)^{\star}$ \\
\hline
\end{tabular}

*Higher than the average prevalence

+ Full information of prevalence of health behaviors can be found in supplementary file 1 .

Abbreviations. VA: Veterans Affairs; IHS: Indian Health Services.

Table 3. Associations of Sociodemographic and Clinical Factors with Unhealthy Behaviors Among Cancer Survivors 


\begin{tabular}{|c|c|c|c|c|}
\hline & Risky Alcohol Use & Current Tobacco Use & Current E-Cig Use & Physical Inactivity \\
\hline & $\mathrm{OR}^{+}(95 \% \mathrm{Cl})$ & $\mathrm{OR}^{+}(95 \% \mathrm{Cl})$ & $\mathrm{OR}^{+}(95 \% \mathrm{Cl})$ & $\mathrm{OR}^{+}(95 \% \mathrm{Cl})$ \\
\hline \multicolumn{5}{|l|}{ Age (years) } \\
\hline $18-49$ & $1.09(0.45,2.67)$ & $0.66(0.29,1.49)$ & $6.84(1.35,34.70)^{*}$ & $1.07(0.49,2.35)$ \\
\hline $50-64$ & $0.87(0.38,2.00)$ & $0.81(0.47,1.40)$ & $2.97(0.78,11.29)$ & $0.96(0.50,1.84)$ \\
\hline $65-74$ & $1.38(0.83,2.31)$ & $1.26(0.90,1.75)$ & $2.65(1.04,6.72)$ * & $0.61(0.42,0.89)$ * \\
\hline$\geq 75$ & Reference & Reference & Reference & Reference \\
\hline \multicolumn{5}{|l|}{ Gender } \\
\hline Male & $1.87(1.10,3.16)^{\star}$ & $1.54(1.07,2.11)^{\star}$ & $1.63(0.85,3.16)$ & $0.94(0.66,1.34)$ \\
\hline Female & Reference & Reference & Reference & Reference \\
\hline \multicolumn{5}{|l|}{ Race/Ethnicity } \\
\hline White & Reference & Reference & Reference & Reference \\
\hline Black/African American & $0.28(0.11,0.74)^{\star}$ & $0.44(0.21,0.93)^{\star}$ & $0.13(0.02,0.73)^{\star}$ & $2.17(1.05,4.48)^{*}$ \\
\hline Hispanic & $0.23(0.09,0.65)^{\star}$ & $0.64(0.32,1.27)$ & $0.83(0.33,2.12)$ & $0.97(0.38,2.44)$ \\
\hline Asian & $0.29(0.01,10.54)$ & $0.35(0.08,1.58)$ & $0.31(0.12,0.79)^{\star}$ & $2.45(0.61,9.88)$ \\
\hline Others & $0.49(0.10,2.50)$ & $1.20(0.42,3.44)$ & $0.37(0.07,2.13)$ & $2.09(0.72,6.07)$ \\
\hline \multicolumn{5}{|l|}{ Education } \\
\hline Less Than High School & $1.06(0.33,3.37)$ & $1.63(0.69,3.85)$ & $4.48(1.01,19.82)^{*}$ & $2.09(0.49,9.00)$ \\
\hline High School Graduate & $0.57(0.27,1.19)$ & $1.96(1.18,3.26)^{*}$ & $3.08(1.31,7.25)^{\star}$ & $1.49(0.89,2.52)$ \\
\hline Some College & $0.75(0.46,1.23)$ & $1.88(1.36,2.61)^{*}$ & $2.15(1.09,4.23)^{\star}$ & $1.49(1.01,2.20)^{\star}$ \\
\hline College Graduate or More & Reference & Reference & Reference & Reference \\
\hline \multicolumn{5}{|l|}{ Household Income } \\
\hline$<\$ 20,000$ & Reference & Reference & Reference & Reference \\
\hline$\$ 20,000$ to $<\$ 35,000$ & $1.15(0.45,2.92)$ & $0.52(0.27,1.03)$ & $0.82(0.30,2.25)$ & $0.96(0.49,1.86)$ \\
\hline$\$ 35,000$ to $<\$ 50,000$ & $1.43(0.58,3.54)$ & $0.71(0.32,1.57)$ & $0.87(0.29,2.58)$ & $1.00(0.49,1.86)$ \\
\hline$\$ 50,000$ to $<\$ 75,000$ & $2.00(0.79,5.04)$ & $0.98(0.47,2.03)$ & $1.39(0.46,4.21)$ & $0.92(0.45,1.86)$ \\
\hline$\geq \$ 75,000$ & $2.11(0.89,5.02)$ & $0.57(0.27,1.23)$ & $0.71(0.22,2.29)$ & $1.04(0.50,2.13)$ \\
\hline \multicolumn{5}{|l|}{ Marital Status } \\
\hline Married & Reference & Reference & Reference & Reference \\
\hline Not married & $1.53(0.91,2.58)$ & $1.24(0.86,1.79)$ & $2.00(1.00,4.00)^{\star}$ & $1.01(0.70,1.45)$ \\
\hline \multicolumn{5}{|l|}{ Area: Rurality } \\
\hline Metropolitan & Reference & Reference & Reference & Reference \\
\hline Micropolitan & $0.31(0.12,0.82)$ & $0.60(0.38,0.97)^{\star}$ & $0.31(0.14,0.69)$ * & $1.34(0.68,2.65)$ \\
\hline Small Town & $0.71(0.19,2.66)$ & $0.53(0.18,1.54)$ & $0.37(0.04,3.85)$ & $0.53(0.21,1.37)$ \\
\hline Rural & $0.71(0.22,2.29)$ & $1.06(0.59,1.90)$ & $1.11(0.24,5.15)$ & $2.13(1.01,4.46)$ * \\
\hline \multicolumn{5}{|l|}{ Health Insurance } \\
\hline Employment and Private & Reference & Reference & Reference & Reference \\
\hline Medicare & $0.41(0.21,0.82)^{\star}$ & $0.78(0.43,1.41)$ & $0.70(0.22,2.25)$ & $1.88(1.08,3.28)^{*}$ \\
\hline Medicaid & $0.28(0.10,0.79)^{*}$ & $0.58(0.27,1.21)$ & $0.66(0.23,1.89)$ & $2.16(1.03,4.55)^{*}$ \\
\hline Tricare, VA, IHS & $0.42(0.17,1.02)$ & $0.94(0.49,1.82)$ & $0.83(0.29,2.39)$ & $1.99(1.09,3.62)^{*}$ \\
\hline \multicolumn{5}{|l|}{ Medical Condition } \\
\hline Heart disease (vs. None) & $1.00(0.49,2.04)$ & $1.35(0.94,1.95)$ & $0.41(0.18,0.96)^{*}$ & $1.27(0.74,2.21)$ \\
\hline Lung disease (vs. None) & $0.97(0.54,1.74)$ & $1.65(1.12,2.41)^{*}$ & $2.25(1.11,4.57)^{*}$ & $1.06(0.69,1.62)$ \\
\hline Depression (vs. None) & $0.77(0.46,1.30)$ & $1.95(1.25,3.03)^{\star}$ & $2.26(1.12,4.56)^{\star}$ & $1.33(0.89,2.01)$ \\
\hline
\end{tabular}


+Adjusted for all the variables in the Table

*P-value $<0.05$

Abbreviations. VA: Veterans Affairs; IHS: Indian Health Services.

Table 4. Associations Between Unhealthy Behaviors Among Cancer Survivors

\begin{tabular}{|c|c|c|c|c|}
\hline & $\begin{array}{l}\text { Risky } \\
\text { Alcohol Use }\end{array}$ & $\begin{array}{l}\text { Current } \\
\text { Tobacco Use }{ }^{++}\end{array}$ & $\begin{array}{l}\text { Current } \\
\text { E-Cig Use }\end{array}$ & $\begin{array}{l}\text { Physical } \\
\text { Inactivity\#\# }\end{array}$ \\
\hline Health behaviors & OR $(95 \% \mathrm{Cl})$ & OR $(95 \% \mathrm{Cl})$ & OR $(95 \% \mathrm{Cl})$ & OR $(95 \% \mathrm{Cl})$ \\
\hline \multicolumn{5}{|l|}{ Alcohol use } \\
\hline light drinkers & N/A & Reference & Reference & Reference \\
\hline moderate/heavy drinkers & N/A & $1.75(1.22,2.52)^{\star}$ & $1.00(0.49,2.03)$ & $0.56(0.38,0.84)^{*}$ \\
\hline \multicolumn{5}{|l|}{ Tobacco Use } \\
\hline Current & $2.12(0.95,4.74)$ & N/A & $58.39(18.46,184.66)^{*}$ & $1.41(0.63,3.19)$ \\
\hline Former & $1.58(1.04,2.41)^{\star}$ & N/A & $14.82(4.76,46.20)^{*}$ & $1.17(0.73,1.86)$ \\
\hline Never & Reference & $\mathrm{N} / \mathrm{A}$ & Reference & Reference \\
\hline \multicolumn{5}{|l|}{ E-Cigarette Use } \\
\hline Current & $1.58(0.39,6.35)$ & $16.40(3.29,81.89)^{\star}$ & N/A & $0.43(0.06,3.08)$ \\
\hline Former & $1.01(0.40,2.55)$ & $10.19(4.70,22.13)^{*}$ & N/A & $2.00(0.65,6.12)$ \\
\hline Never & Reference & Reference & N/A & Reference \\
\hline \multicolumn{5}{|l|}{ Physical Activity } \\
\hline 0-150 minutes & Reference & Reference & Reference & $\mathrm{N} / \mathrm{A}$ \\
\hline$>150$ minutes & $1.74(1.15,2.63)^{\star}$ & $0.90(0.59,1.37)$ & $0.57(0.23,1.40)$ & N/A \\
\hline
\end{tabular}

+Adjusted for other health behaviors in the Table and gender, race/ethnicity and health insurance.

${ }^{++}$Adjusted for other health behaviors in the Table and gender, education, race/ethnicity, rurality, lung disease and depression.

\#Adjusted for other health behaviors in the Table and age, race/ethnicity, education, marital status, rurality, heart disease, lung disease and depression.

\#\#Adjusted for other health behaviors in the Table and age, race/ethnicity, education, rurality, health insurance and psychological distress.

${ }^{*}$ P-value $<0.05$

\section{Supplementary Files}

This is a list of supplementary files associated with this preprint. Click to download.

- SupplementaryInformationKimetal..xIsx 